\title{
A Study on the Writing Strategy Using Example Article of Korean Language Learners
}

\author{
Sang-soo Kim $\left.{ }^{1}\right)$
}

\begin{abstract}
The purpose of this study is to examine the writing strategies of Korean language learners. For this, an example article was presented to intermediate level Korean language learners. The study participants included 20 Chinese students in intermediate courses at a university's Korean language institute. The structure of the example text presented to the learners in this study is a comparative-control explanation. In the introduction, described as a whole, and the main text provides information on the similarities and differences between opera and pansori. The conclusion explains the commonalities and differences between opera and pansora. In order to improve the writing ability of Korean language learners, rather than focusing on the results or sequential processes after writing, it is necessary to use these two complementarily to produce high-quality writing. In particular, to achieve academic success for academic purpose learners, it is necessary to provide continuous attention and training so that learners can generate the structure and content of the writings themselves.
\end{abstract}

Keywords: Korean Language Class, Academic Purpose Learner, Writing Strategy, Imitation Strategy, Example Article, Text Structure

\section{Introduction}

The purpose of this study is to examine the writing strategies using the example article of Korean Language learners. For this, an example article was presented to intermediate level Korean language learners. This study will also look at how learners use the structure of an example text in new writing[1].

Writing is the process of communicating thoughts, feelings, and information to the reader. In order to facilitate the process of communication, learners need very complex and diverse skills[2]. However, most learners are not accustomed to writing in connection with these complex and diverse thinking processes, which is the same phenomenon for Korean language learners. In particular, Korean language learners frequently encounter difficulties in writing for academic purpose, which is an academic and professional Korean language expression function

Received(September 20, 2019), Review Result(1st: October 16, 2019, 2nd: December 02, 2019), Accepted(February 20, 2020)

1) (Assistant Professor) 48520 School of Interdisciplinary, Major in Korean Language Education, Tongmyong Univ., Sinseonro 428, Nam-gu, Busan, Korea

email: kospora@naver.com 
during their studies at university and graduate school after completing a language course.

Academic purpose learners will publicly, write reports or presentations related to their major subjects[3]. This public writing is also associated with public speaking, such as presenting or discussing topics. Thus, writing activities are not just expressive activities, but also require the learner's ability to explain and persuade the listener with the reader's understanding. However, this writing ability does not improve naturally when Korean language communication ability improves to an advanced level.

Writing is not merely a statement of words. Writing has a more complex structure than other language functions because it selects, organizes, and expresses the content of a text through the emotions, experiences, and thoughts of the author. Writing skills are difficult to perform smoothly even in advanced stages unless they are systematically and continuously developed from the beginning[4]. Therefore, in order to cultivate the writing skills necessary for academic purposes, learners of Korean language should emphasize learning writing from the beginner level to eliminate the burden and fear of writing itself.

There have been discussions about how to use reading texts at the stage of writing in Korean language education. Lee (2008) presented the possibility of using integrated reading and writing education, and Kim (2009) explained the use of various texts to improve the comprehension of content knowledge of Korean learners for academic purposes[5][6]. Choi (2009) used reading texts in the planning stage for writing based on cognitive constructivist writing theory and models[7]. In Lee (2011), Korean learners with an academic purpose have a great ability to understand and use materials in writing situations[8]. Choi (2012) explained that education on discourse integration, which analyzes various external texts in their own way and rearranges them from their own perspectives and integrates them with their own knowledge, is very necessary[9]. In addition, Kim (2013) stated that it is necessary to provide reading materials in order to proceed to the pre-writing stage as a preliminary study when preparing an educational model for Korean learners to learn academic writing.

Foreign learners attending undergraduate or graduate schools need a wide variety of academic and professional writing skills[10]. However, a lack of writing skills often lead to difficulty in studying major subjects. Many skills are required to carry out the academic and professional writing required by a university[11]. Of particular importance is the ability to read and summarize and synthesize various texts. Students also need to be able to persuade others by coherently organizing the contents of a text. Therefore, international students need the ability to analyze existing texts and write new texts using them. 


\section{Method}

\subsection{Participants}

The study participants included 20 Chinese students in intermediate courses at a university's Korean language institute. Seventeen participants were TOPIK(Test of Proficiency in Korean) Level 3, and three were TOPIK Level 4. The Participants ranged in age from 19 to 24 years, with six males and 14 females. Their purpose for learning the Korean language was to enter a university or graduate school in Korea.

[Table 1] Participants

\begin{tabular}{l|l}
\hline Gender & $\begin{array}{l}\text { Male } 6 \\
\text { Female 14 } \\
\text { Total 20 }\end{array}$ \\
\hline Nationality & China \\
\hline Age & $19 \sim 24$ \\
\hline $\begin{array}{l}\text { Korean } \\
\text { proficiency }\end{array}$ & TOPIK Level 3 17 \\
\hline
\end{tabular}

\subsection{Data Analysis}

Participants were provided with an example article comparing and contrasting opera and pansori. The structure of the example text is as follows.

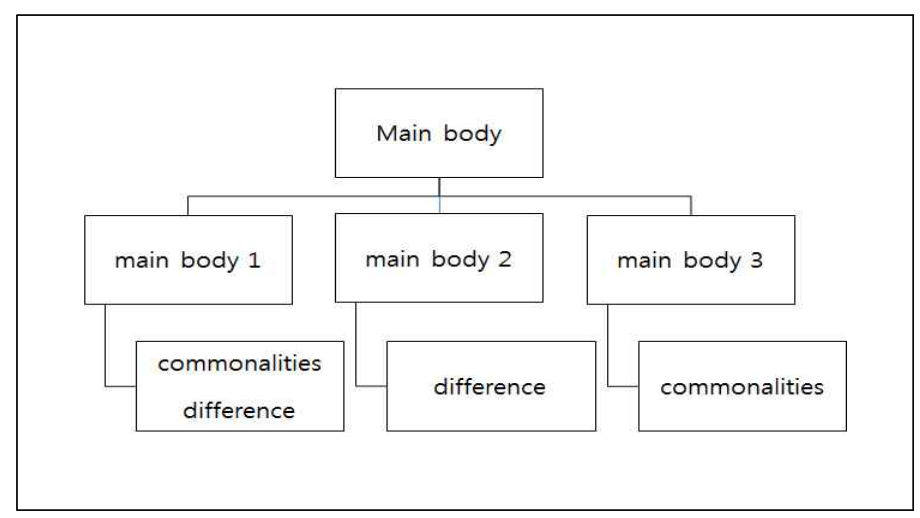

[Fig. 1] Text Structure 
In addition, after reading the example article, the learners were also asked to grasp the content and structure. The Participants were asked to write an article comparing hanbok and qipao based on the example article. At this time, basic content information was provided for hanbok and qipao that corresponded to the material of the text to help learners create the content of the text. The contents of the example and the information presented for the writing activity are as follows.

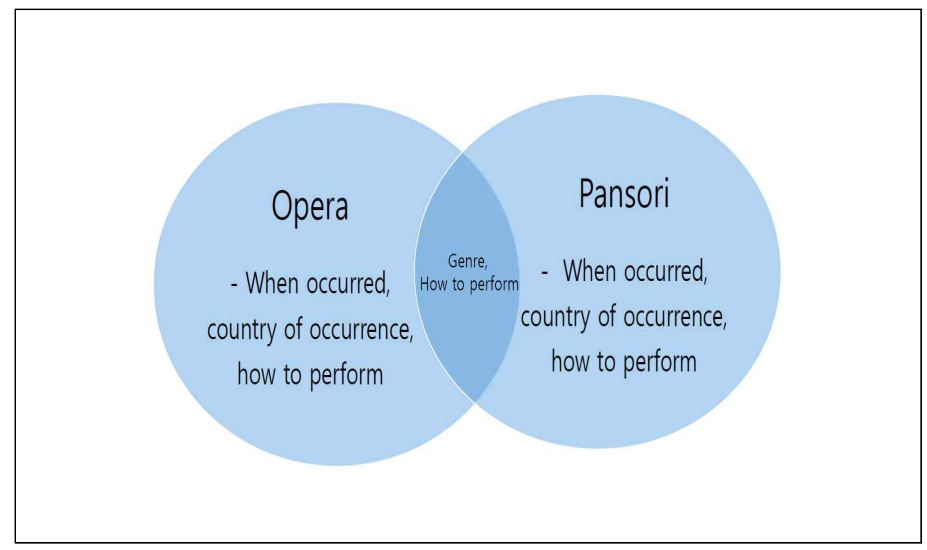

[Fig. 2] Text Content

The content of the example article is a balanced arrangement of information on the commonalities and differences between opera and the pansori. Therefore, learners should write about hanbok and qipao so that the commonalities and variations can be clear and balanced. The example text is also a comment with a comparative-control structure. Therefore, the learner should complete the article similar to the structure of the example article.

\subsection{Collection Procedure}

The writing process for importing data is as follows. In the pre-writing stage, learners were provided with example texts and then used a copy-writing strategy to complete a new comparative-control article. The learner analyzes the text structure and text content in the example text provided in the pre-writing stage. They also organize and create topics, text structures, and text content for writing a new text. In the writing stage, the contents of the example text and the information provided are used to imitate the content structure, and they proceed to draft a text. In the post-writing phase, the contents of the writing are corrected and supplemented, and the completion of the writing is improved through the teacher's feedback. 


\begin{tabular}{|c|c|}
\hline Stage & Contents \\
\hline pre-writing stage & $\begin{array}{l}\text { - Analyzing text } \\
\text { - Looking at topics and information } \\
\text { - Creating and organizing content }\end{array}$ \\
\hline \multicolumn{2}{|l|}{$\downarrow$} \\
\hline writing stage & - Writing \\
\hline \multicolumn{2}{|l|}{$\downarrow$} \\
\hline post-writing stage & $\begin{array}{l}\text { - Revising } \\
\text { - Editing } \\
\end{array}$ \\
\hline
\end{tabular}

[Fig. 3] Writing Procedure

\section{Result}

The structure of the example text presented to the learners in this study is a comparative-control explanation. In the introduction, the genres of opera and pansori are described as a whole, and the main text provides information on the similarities and differences between opera and pansori. The conclusion explains the commonalities and differences between opera and pansora.

\subsection{Text Structure}

The structure of the example text given to the learners in this study is a comparative-control explanation. The Introduction briefly introduces the genres of opera and pansori, and the main body provides a variety of information by listing commonalities and differences between opera and pansori.

After the learners were provided with the example articles, they understood the structure of the articles and used them to organize new articles. However, although the overall structure of the article has the form of an introduction, main body, and conclusion, it was found that the proper amount of contents provided in the example article could not be written for each stage. The structure of the text produced by - "Learner 20" - was only the introduction and main body, and no conclusion. The text produced by - "Learner 3" - was cohesive, and it could be seen that the beginning, middle and end of the writing were closely connected to each other.

- Every country has its own traditional dress. The same is true of Korea and China. 
$<$ Omitted> What both hanbok and qipao have in common is that they are clothes worn on New Year's Day. However, Korea and China have cultural differences, so hanbok and qipao also differ. Hanbok ..... qipao ...... Hanbok and qipao are also different in how to wear them. On the other hand, hanbok and qipao are the traditional clothes of the country and are worn on the New Year's holiday's Day. As such, hanbok and qipao are traditional clothes of Korea and China and can represent the culture of their country. In addition, due to the development of the design of their country, the appearance of the clothes became more diverse and the style became more beautiful. As time goes by, you will see more beautiful hanbok and qipao. [P3]

In the article produced by - "Learner 7"-, there are some common points and differences between hanbok and qipao in the main part. However, the flow of the writing is unnatural because the contents of the concluding section do not match the contents of the main body. The semantic relations between sentences are not linked because they only list the preferred objects rather than comparing them. Therefore, in order to improve the learner's self-directed writing ability, it is necessary to provide example articles and analyze the structure of the text. It is also necessary to educate people on how to use their analysis in writing.

- Every country has its own traditional clothes. Traditional Korean clothes are hanbok and representative Chinese clothes are qipao. The two countries have many similarities in traditional culture, but there are many others. Hanbok is a garment that hides a woman's figure from the big picture. <Omit> So, Korean women think that wearing Hanbok is more pretty and cute. China's qipao is different for each person. <Omit> So women wearing qipao look really elegant and feminine. Different people think differently, but I prefer qipao more. According to the cultural background of the country in which the clothes were formed, they developed into a form that has its own unique characteristics. [P4]

\subsection{Text Contents}

The example article presented in this study has well-arranged information on the commonalities and differences between opera and pansori, and the commonalities and differences are evident in the text. In addition, in this paper, the structure of the text is organized systematically from simply listing common points and differences for the two subjects. In the article on hanbok and qipao completed by the learners, 13 learners arranged and organized information about each subject well, but two learners simply arranged the information about the subject. In addition, 
five learners completed the article with explanations of hanbok and qipao, but not comparison-control writings. The following is an example of an article completed by - "Learner $5^{\prime \prime}$ - by grasping the content structure of the example article.

- Hanbok and qipao are common in that they are worn on New Year's Day, but there are also differences because of cultural differences between Korea and China. Korean have worn hanbok since ancient times, and the appearance of the clothes is becoming more and more beautiful over time. In addition, hanbok are a large clothes that are comfortable for fat people to wear. On the other hand, qipao are a clothes that appeared in modern times and are not big but attached to the body, and are pretty for slim people but uncomfortable for fat people. $<$ Omitted $>$ On the other hand, hanbok and qipao are the traditional clothes of the country, they are worn on the New Year holiday, and they can be found in common. [P5]

However, - "Learner 6" - takes the form of a simple sequence that describes the differences and the commonalities between the two objects. The analysis of the model text does not appear to be accurate.

- First, the commonalities of qipao and hanbok will be explained. <Omit> Next, explain the difference between qipao and hanbok [P6]

- "Learner 13" - does not suggest the commonalities of hanbok and qipao in the main part, but shows only the differences, so that the content structure of the text is unbalanced.

- There are many differences between hanbok and qipao. We will now compare hanbok and qipao. First, hanbok can be worn by both men and women, depending on the shape. Qipao can only be worn by women. Secondly, there are many kinds of hanbok including jeogori, skirt, beosean, dulumagi, etc. However, qiapo is convenient to wear because only one piece is worn. [P13]

- "Learner 10" - wrote a comparison-control article on hanbok and qipao in the main section. However, the contents are listed in the description of hanbok and qipao without clear distinction between commonalities and differences.

- Hanbok is a traditional Korean costume. The combination of straight lines and slight curves is beautiful, especially for women's clothes, which are neatly dressed with a short jeogori 
and a generous skirt. It is divided into robes and casual clothes, and is divided into men's and women's seasons. <Omit> Qipao is a traditional Chinese costume formed in the Qing dynasty. Originally, there were both men's and women's costumes, but now there is only one piece of women's clothing. The clothing fits perfectly to the side of the skirt so that practicality and feminine beauty are important. [P10]

\section{Conclusion}

In this study, we provided an exemplary article for intermediate-level Chinese Korean learners and used imitative strategies. Most learners completed their writings appropriately using the examples provided, and some learners were unfamiliar with using them to complete their writings.

In order to improve the writing ability of Korean language learners, rather than focusing on the results or sequential processes after writing, it is necessary to use these two complementarily to produce high-quality writing. In particular, in order to achieve academic success for academic purpose learners, it is necessary to provide continuous attention and training so that learners can generate the structure and content of the writings themselves.

In this study, we provided writing examples in the pre-writing stage as a teaching strategy according to the writing process and applied a writing imitation strategy, one of the result-oriented writing methods. And through this, we could explore the possibility of writing imitation strategies necessary for teaching instruction and the writing ability of Korean language learners for academic purposes. In addition, it was found that learners need step-by-step exercises to analyze, structure, and utilize external texts before the advanced stage.

However, the failure to observe changes by continuously observing using writing imitation strategies or to set a control group. It is remain limitations and will be reveal through future studies.

\section{References}

[1] D. Nunan, Second language teaching and learning, Heinle \& Heinle, (1999)

[2] M. S. Knowles, Self-Directed Learning: A guide of learners and teachers, Assocation Press, (1975)

[3] H. D. Brown, Principles of Language Learning and Teaching (5th ed.), White Plains, NY : Pearson Education, (2007) 
[4] C. Kim, Academic Writing Instruction Model Using Integrated Activity of Reading and Writing, Bilingual Research, (2007), No.33, pp.35-54, DOI: 10.17296/korbil.2007..33.35

[5] D. Lee, Teaching Essay Writing through a Imitation Strategy : By Using the Brganization of Jeonron by Jeong Yak Yong, Kyungnam University, Master's Thesis, (2008)

[6] M.. Kim, A Study on the Effects of Learning the Text Structure(causation, problem/solution and comparison) upon Korean Writing, The International Association For Korean Language Education, (2007), Vol..18, No.3, pp.27-51. DOI: 10.18209 /iakle.2007.18.3.27

[7] Y. Choi, A study on Korean writing teaching methods utilizing reading texts, Hankuk University of Foreign Studies, Master's Thesis, (2009)

[8] J. Lee, The Study on Reading-to-write Task for KAP Learners, Journal of Korean Language Education, (2011), Vol.22, No.4, pp.83-108.

[9] E. Choi, A Study on Aspects of Discourse Synthesis of Advanced Korean Learners, Bilingual Research, (2012), No.49, pp.381-410.

[10] S. Lee, A Research on the Integrated Reading and Writing Teaching Method for KFL(Korean as a Foreign Language) Learners, Bilingual Research, (2008), No. 37, pp.113-131.

[11] J. Choi, Effects of implementing cognitive constructivist writing strategy on students in a Korean as foreign language (KFL) class, Teaching Korean as a Foreign Language, (2008), Vol.33, pp.227-260, UCI : G704-SER000010512.2008.33..009 